\title{
Modelling and Predicting of the Characteristics of a Photovoltaic Generator on a Horizontal and Tilted Surface
}

\author{
Mustapha Elyaqouti ${ }^{1}$, Lahoussine Bouhouch ${ }^{2}$, Ahmed Ihlal ${ }^{3}$ \\ ${ }^{1,2}$ ERTAIER, ESTA Ibn Zohr University, BP 33/S, 80000 Agadir, Morocco \\ ${ }^{3}$ LMER, FS Ibn Zohr University, BP 8106, 80000 Agadir, Morocco
}

\begin{tabular}{l}
\hline \hline Article Info \\
\hline Article history: \\
Received Jul 4, 2016 \\
Revised Oct 19, 2016 \\
Accepted Nov 2, 2016
\end{tabular}

Keyword:

Kasten model

Prediction

PVG modeling

Solar radiation

\begin{abstract}
In the present paper, we will attempt to predict the $I_{p v}-V_{p v}$ output characteristic of a photovoltaic generator $(P V G)$ and consequently the generated electric power. This will be possible through modeling, extracting the electrical parameters of the $P V G$ under study and also, by estimating the global incident solar radiation, on a surface, first horizontally, and then tilted to a given angle. Mathematical models developed in Matlab, to characterize the studied PVG are validated by experimental data of the PVG manufacture. While models associated with global radiation are validated by measurements taken by the meteorological station installed on the laboratory site ERTAIER (Team for Research in Technology and Advanced Engineering of Renewable Energies) of Higher School of Technology Agadir (ESTA).
\end{abstract}

Copyright $\Subset 2016$ Institute of Advanced Engineering and Science. All rights reserved.

Corresponding Author:

Mustapha Elyaqouti,

ERTAIER, ESTA Ibn Zohr University,

BP 33/S, 80000 Agadir, Morocco.

Email: elyaqouti@gmail.com

\section{INTRODUCTION}

Solar energy is recognized as a promising alternative solution to the problems of fossil fuel depletion and global warming. We have witnessed in the last decade that Renewable Energies are providing more and more significant part in the energy mix in some countries. Photovoltaic conversion (PV), for instance, is expected to play a major role in electricity supply. Solar PV is covering more than $7 \%$ of the electricity demand in many countries in Europe. By 2050, PV's share of global electricity is expected to reach $16 \%$. However, the intermittency of solar impacts on security of energy supply.

Thus, the accurate modeling of photovoltaic generators is a major concern because it allows the designer to optimize performance and maximize the profitability of such PV systems [1].

The study of the PV functioning systems in steady state requires the development of models to estimate the amount of energy to be produced by a given PV system. These models are classified into two types: First, those that model the efficiency of a PVG, usually based on a direct expression for estimating the maximum power of PVG. The Second are those that model the current and voltage of the module and consequently the electrical power supplied by the PVG [2]. This modeling is typically used to approximate the output of PVG according to the two inputs that are solar radiation and module temperature, which is none other than the operating temperature of the photovoltaic cells [3]. However, the needed data are not available on all sites, for this reason, we have to use some approximate methods for predicting incident solar radiation on a horizontal surface or tilted at a given angle.

In this work, we propose an approach that allows the prediction of the output characteristics $I_{p v}-V_{p v}$ of a given PV module for different inclinations. This will permit us then, the deduction of the maximum power generated by the PV module under study at any time and any day of the year.

The block diagram of the model we have developed in Matlab is shown in Figure 1. Our model 
calculates the $G$ incident solar irradiance on a horizontal surface, while calculating the direct solar irradiance $G_{d i r}$ and diffuse $G_{\text {diff. }}$ Once it has been given the day number n, hour $h$ or True Solar time (TST) and geographical coordinates of the place, given by latitude $\varphi$, longitude $L$ and altitude $Z$. From the values of $G_{d i r}$ and $G_{d i f f}$, we can determine the value of the incident solar radiation $G_{\beta}$ on an $\beta$ angle tilted surface. After this phase, the knowledge of $G_{\beta}$ and cells temperature $T_{\text {cell }}$ are sufficient to the prediction of the output characteristic $I_{p v^{-}} V_{p v}$, and therefore the simulated maximum power $P_{\max , s}$ of the studied $P V G$.

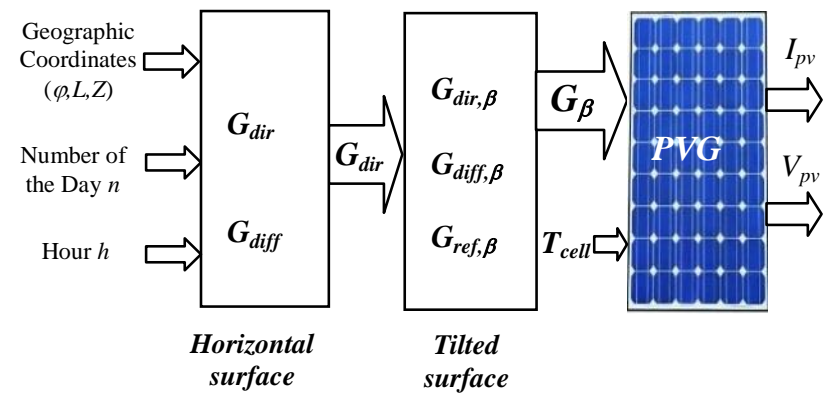

Figure 1. Diagram Block of Developed Model

Our paper is organized as follows: after an introduction, Section 2 describes the site concerned by the used meteorological measurements. Section 3 discusses the modelling of the incident solar radiation on horizontal and/or tilted surfaces. Then, we present in section 4 the modelling and characterization of the studied PVG. A conclusion and future prospects are presented at the end of this document.

\section{SITE AND METEOROLOGICAL MEASUREMENTS}

The meteorological data such as direct and diffuse solar radiation, ambient temperature, humidity and the wind speed and direction are collected by various sensors connected to a Campbell data logger CRX10X installed at the ERTAIER Laboratory at the higher school of technology (ESTA) Agadir (Figure 2). The data are collected every 10 seconds. They can be presented in different formats: average, min, max, etc., according to the chooses configuration in the data logger [4-5]. The data used in this work are related to Agadir site for which the geographical coordinates are:

- Longitude $\varphi=9.579^{\circ} \mathrm{W}$,

- Latitude $L=30.406^{\circ} \mathrm{N}$ and

- Elevation $Z=41 \mathrm{~m}$.

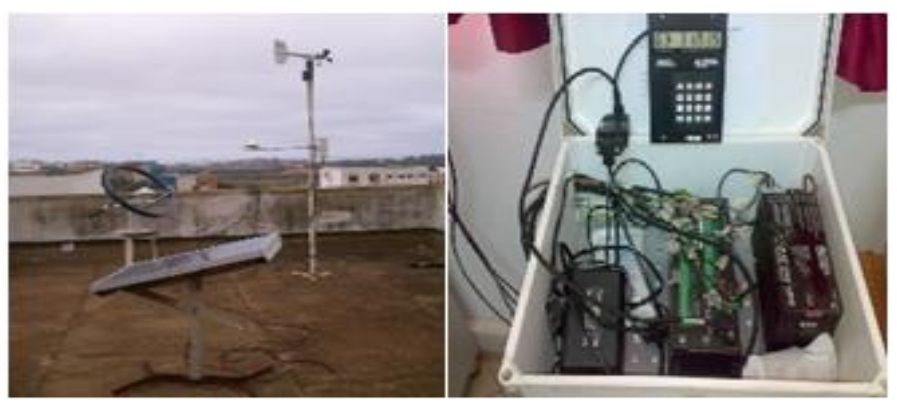

Figure 2. Meteorological Station Campbell Data Logger CRX10X

\section{SOLAR RADIATION MODELING}

In this section, we present the procedure for modeling the incident solar radiation on a horizontal surface first and then $\beta$ angle tilted. To achieve this, we will discuss the theory of atmospheric and geometric parameters used to estimate the solar radiation. 


\subsection{Atmospheric and Geometric Parameters Modeling}

\subsubsection{Earth Geographic Coordinates}

These celestial ecliptic coordinates, are angular coordinates that identify a point or a place on the earth. It is a three coordinate system which are: the latitude, longitude and altitude. This coordinate system is shown in Figure 3.

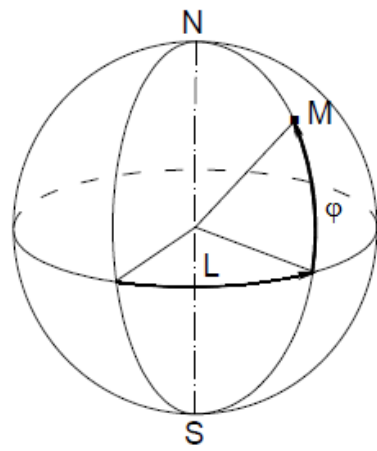

Figure 3. Earth geographic coordinates

\subsubsection{Latitude $\varphi$}

It is the angle between the equator plane and the direction connecting the center of the earth at the considered point. Its value is positive in the northern hemisphere while it is negative in the southern hemisphere [6].

\subsubsection{Longitude $L$}

It is the angle that the local meridian, passing through the point in question, with the meridian of origin, passing through the town of Greenwich. Its value is positive in the West while it is negative in the east of the origin meridian [7].

\subsubsection{Altitude $Z$}

It is the elevation of a location above the sea level, measured in meters.

\subsubsection{Locating the Sun Position}

The apparent movement of the sun is the movement that seems, to be done in a day, by the sun for an observer on the Earth installed outside the polar regions [8]. The apparent position of the sun is identified, every moment on the day and a year by two different coordinate systems: The hours celestial coordinate and horizontal celestial coordinates [9].

\subsubsection{The Hours Celestial Coordinate}

a) Sun Declination $\delta$

The declination $\delta$ is the angle formed by the direction Earth-Sun relative to the Earth's equator [10]. It is expressed in degrees $\left({ }^{\circ}\right)$, in minute (') and seconds ("). This angle varies very little within a day and its value ranges from $-23.45^{\circ}$ at the winter solstice and $+23.47^{\circ}$ at the summer solstice and it is zero at the equinoxes of spring and autumn. It is calculated by the following equation [11]:

$$
\delta=23.45 \sin [360 *(284+n) / 365.25]
$$

b) Hour Angle of the Sun $H$

This is the angle between the prime meridian passing through the south, and the projection of the sun on the equatorial plane (Figure 4). It measures the sun's path in the sky [12]. It is counted positively in the morning and negatively at the afternoon [13]. It increases by five degrees per hour.

$H$ is given by the following expression [6]:

$$
H=15^{\circ}(R T S-12)
$$


$R T S$ is counted from 0 to $24 \mathrm{~h}$. It is calculated by the following relation:

$$
R T S=T_{\text {legal }}+E T-\frac{L-L_{\text {ref }}}{15}-C
$$

where:

- $\quad E T$ is the correction of the equation of time, due to the variation in the speed of the earth on its path around the sun. This correction varies between14minutes minimum and 17 minutes maximum [9]. As a Function of the day number $n$, counted from 1 to $365, E T$ is expressed by the following expression [14]:

$$
\begin{aligned}
E T= & -0.0002+0.47497 \cos (x)-7.3509 \sin (x)-3.2265 \cos (2 x)-9.3912 \sin (2 x) \\
& -0.0903 \cos (3 x)-0.3361 \sin (3 x)
\end{aligned}
$$

with:

$$
x=360 n / 366
$$

- $\quad T_{\text {legal }}$ : Legal Time is the time that is commonly used. It is shifted by a integer number of hours compared to the origin time (Meridian 0).

- $\quad L-L_{\text {ref: }}$ Longitude difference between a considered place and the longitude reference in standard time.

- $\quad C$ : Time difference that is the difference between the standard time and the calendar time zone where it is located.

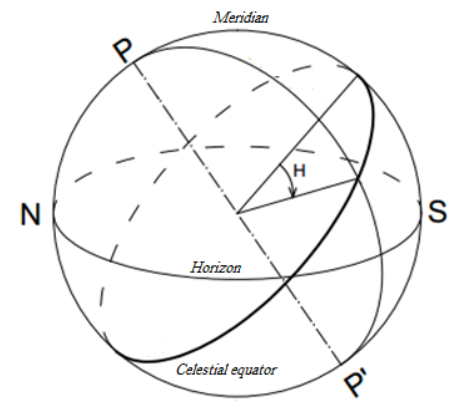

Figure 4. Hours Celestial Coordinate

\subsubsection{Horizontal Celestial Coordinates}

This coordinate system (Figure 5) has a reference the horizontal plane. The sun is located by two components: its altitude angle $h$ and its azimuth $a$.

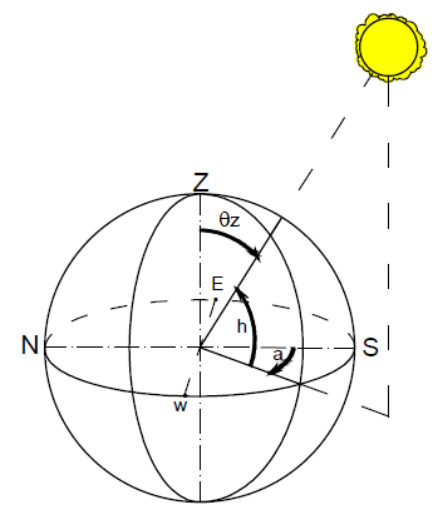

Figure 5. Horizontal Celestial Coordinates 
a) Sun Altitude h

This is the angle between the apparent direction of the sun and its projection on the horizontal plane [12], [9], $h$ may vary during the dayfrom $0^{\circ}$ (sun on the horizon) to $90^{\circ}$ (midday sun). $h$ is a function of the declination $\delta$, the latitude $\varphi$ and the hour angle $H$ according to the following relation [6]:

$$
\sin (h)=\cos (\delta) \cos (\varphi) \cos (H)+\sin (\varphi) \sin (\delta)
$$

b) Sun Azimuth $\mathrm{a}_{\mathrm{s}}$

It is the angle between the projection of the sun direction on the horizontal plane and north or south direction. It is comprised between $-180^{\circ}$ and $+180^{\circ}$. According to $\delta$ declination, the hour angle $H$, the height $h$ and the longitude $L$, the azimuth is calculated by the following equations [13]:

The angle between the direction of the sun with the vertical is called zenith angle $\theta_{Z}$. It varies from $0^{\circ}$ to $90^{\circ}$ according to the following relation:

$$
\theta_{z}=90^{\circ}-h
$$

According to declination $\delta$, the latitude $\varphi$ and height $h$, the zenith angle $\theta_{z}$, it can be calculated by:

$$
\cos \left(\theta_{z}\right)=\cos (\delta) \cos (\varphi) \cos (h)+\sin (\varphi) \sin (\delta)
$$

\subsubsection{Plane Orientation}

An arbitrary orientation plane as illustrated in Figure 6 can be located by two angles $h_{p}$ and $a_{p}$ with:

$h_{p}$ : The height of the plane is the angle between the normal $\vec{n}$ to the plane and its projection on the horizontal plane.

$a_{p}$ : Plane azimuth that represents the angle between the projection of the normal $\vec{n}$ on the horizontal plane and south direction [12].

The inclination of the plane relatively to the horizontal plane is designated by $\beta$ angle. This latter varies between $0^{\circ}$ and $90^{\circ}$. This angle is given by the following formula [12]:

$$
\beta=90^{\circ}-h_{p}
$$

The angle between the direction of the sun and the normal $\vec{n}$ to the plane is called incidence angle $\theta_{i}$, which is determined by the following equation [15]:

$$
\begin{aligned}
& \cos \left(\theta_{i}\right)=\sin (\delta) \sin (\varphi) \cos (\beta)-\sin (\delta) \cos (\varphi) \sin (\beta) \cos \left(a_{p}\right) \\
& \quad+\cos (\delta) \cos (\varphi) \cos (\beta) \cos (H)+\cos (\delta) \sin (\varphi) \sin (\beta) \cos \left(a_{p}\right) \cos (H) \\
& \quad+\cos (\delta) \sin (\beta) \sin \left(a_{p}\right) \sin (H)
\end{aligned}
$$

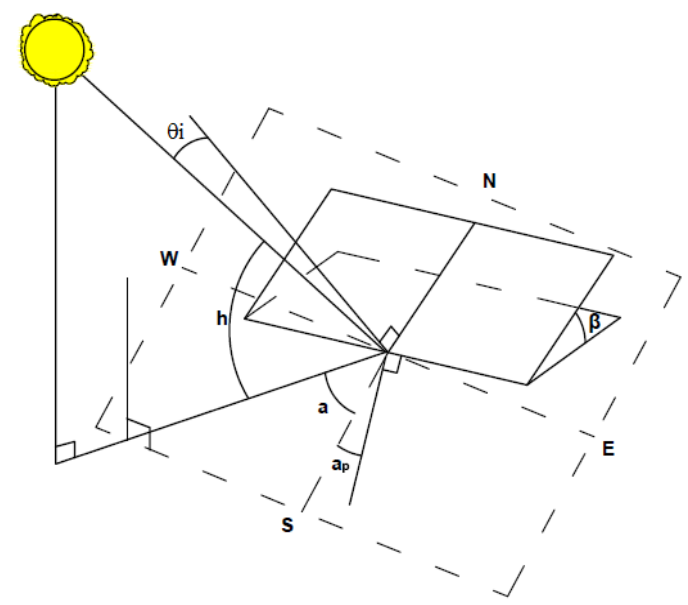

Figure 6. Plane Orientation 


\subsection{Modeling of the Incident Solar Radiation on a Horizontal Plane}

The global solar radiation $G$ on a horizontal plane is the sum of two components: the direct solar radiation and diffuse solar radiation [16] (Figure 7).

$$
G=G_{\text {dir }}+G_{\text {diff }}
$$

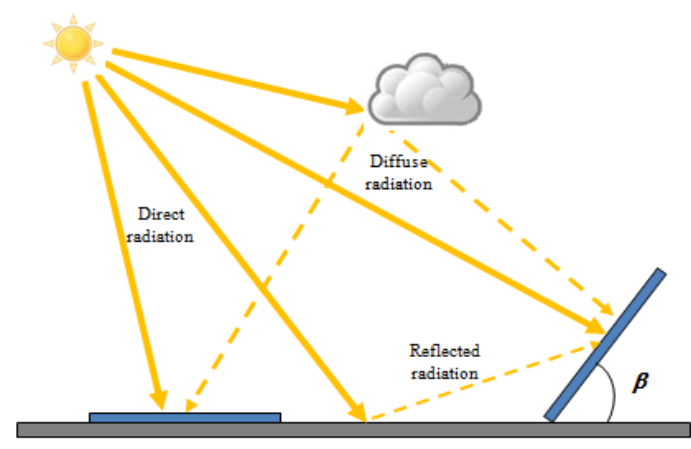

Figure 7. Global Solar Radiation Received on a Horizontal Planeand on a Tilted One

- The direct radiation $G_{d i r}$ is a quasi-parallel solar irradiance, coming from the solar disc intercepted most of the time, by a normal surface to the direction of the sun. It is measured by a Pyrheliometer.

- The diffuse radiation $G_{\text {diff }}$ is a solar radiation received by any surface and coming from the whole hemisphere seen from the surface except the solar disk. It is measured using a pyranometer protected from direct solar radiation by a screen.

The direct solar radiation on a horizontal plane is given by the following equation [13]:

$$
G_{d i r}=I^{*} \sin (h)
$$

where $I^{*}$ is a direct sun light incident on the Earth surface of, it is expressed by the following formula [17]:

$$
I^{*}=\left(I_{0}\right)_{e x t} \exp \left[-\frac{m_{h} T_{L}}{0.9 m_{h}+9.4}\right]
$$

with:

- $\quad\left(I_{0}\right)_{\text {ext }}=1366 \mathrm{~W} / \mathrm{m}^{2}$ : The constant corresponding to the extraterrestrial solar radiation;

- $\quad m_{h}$ :The atmospheric optical distance, called air mass $(\mathrm{m})$. This latter is the ratio of the traveled distance in the atmosphere by a ray coming from the sun to the vertical thickness of the atmosphere measured at sea level [9]. For $\mathrm{Z}$ altitude, atmospheric mass expressed by using the following equation applied by Kasten in 1959 [17]:

$$
m_{h}=\frac{1-0.1 Z}{\sin (h)+0.15(h+3.885)^{-1.253}}
$$

- $\quad T_{L}$ : Is the Linke turbidity factor. It gives an evaluation of the atmospheric extinction by gaseous molecules and aerosols. Its average value is given by the following relation [9]:

$$
T_{L}=2.5+16 \beta_{A}+0.5 \ln (w)
$$

where: 
- $\quad \beta_{A}$ is the Angstrom coefficient that characterizes the clarity of the sky. This coefficient is determined by the number of aerosols enclosed in an air mass unit vertically at the measurement place. The Table 1 gives some values;

- $\quad w$ is the height of condensable water (in $\mathrm{cm}$ ). It corresponds to the respective thickness of water that would be obtained by the condensation of any water vapor contained in a hypothetical cylinder with the axis parallel to the solar rays. The table 1 gives some values.

Table 1. Values of the Angstrom Coefficient and the Condensable Water Height for Three States Atmospheric

\begin{tabular}{lcc}
\hline \multicolumn{1}{c}{ Case } & $\beta_{A}$ & $w(\mathrm{~cm})$ \\
\hline The clear sky & 0.05 & 1 \\
Sky moderately cloudy & 0.1 & 2 \\
Sky very cloudy & 0.2 & 5 \\
\hline
\end{tabular}

The diffuse radiation is given by the following equation [14]:

$$
G_{\text {diff }}=\frac{\left(I_{0}\right)_{\text {ext }}}{25} \sqrt{\sin (h)}\left[T_{L}-0.5-\sqrt{\sin (h)}\right]
$$

\subsection{Modeling of the Incident Solar Radiation on a Tilted Plane}

In order to better quantify the amount of solar radiation received by the inclined PV modules, some kind of correction should be made regarding the solar radiation on a horizontal surface. This task will be necessarily for estimating the incident radiation received by an inclined surface.

The general shape of the overall radiation received on a $\beta$ inclined plane is given by:

$$
G_{\beta}=G_{\text {dir }, \beta}+G_{\text {ref }, \beta}+G_{\text {diff }, \beta}
$$

The incident direct solar radiation on an inclined surface $G_{d i r, \beta}$ can be estimated by multiplying its value on a horizontal surface $G_{d i r}$ by a geometric factor $R_{b}$ which depends on the zenith angle $\theta_{Z}$ and the incidence angle $\theta_{i}$ which depends on $\beta$ according to the equation (11). Thus, the following relation gives $G_{d i r, \beta}$ :

$$
G_{d i r, \beta}=G_{d i r} R_{b}=G_{d i r} \frac{\cos \left(\theta_{i}\right)}{\cos \left(\theta_{z}\right)}
$$

The solar radiation reflected by the ground and received by a tilted plane can be estimated by multiplying the total radiation on a horizontal surface $G$ by the ground reflectance $\rho$ called albedo, and the visibility factor between the surface and the ground, as shown by the equation below [18]:

$$
G_{r e f, \beta}=\frac{1}{2} \rho G(1-\cos \beta)
$$

The diffuse solar radiation on the inclined plane, can be evaluated according to the model Klucher [19] given by the following equation:

$$
G_{\text {diff }, \beta}=G_{\text {dir }}\left[0.5\left(1+\cos \left(\frac{\beta}{2}\right)\right)\right]\left[1+F \sin ^{3}\left(\frac{\beta}{2}\right)\right]\left[1+\cos ^{2}\left(\theta_{i}\right) \sin ^{3}\left(\theta_{z}\right)\right]
$$

with:

$$
F=1-\left(\frac{G_{\text {diff }}}{G}\right)^{2}
$$




\section{MODELING OF PVG}

In this section, we present three models for modeling the electrical characteristics of our PVG.

\subsection{Simplified Model with a Single Diode with Rs}

4.1.1. Presentation of Rs Model

This model is a simplified model based on the equivalent circuit with a diode given in Figure 8 . The characterizing equation of this model is as follows [21-22]:

$$
I_{p v}=I_{p h}-I_{0}\left[\exp \left(\frac{q\left(V_{p v}+R_{s} I\right)}{n_{s} a K T_{\text {cell }}}\right)-1\right]
$$

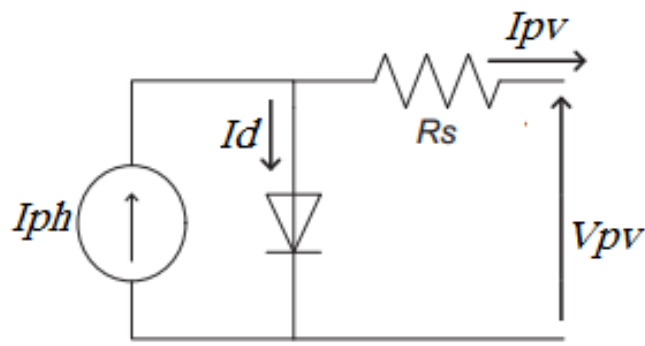

Figure 8. Rs Model

In the following, we assume the approximation $I_{p h}=I_{s c}$ where $I_{s c}$ is function of the temperature of the cells $T_{\text {cell }}$ and the radiation $G_{\beta}$, this current is expressed by:

$$
I_{s c}=I_{s c, r e f}\left[1+\alpha_{0}(\Delta T)\right] \frac{G_{\beta}}{G_{\beta, r e f}}
$$

$\Delta T$ is the temperature difference, which is calculated by the equation:

$$
\Delta T=T_{\text {cell }}-T_{\text {cell }, \text { ref }}
$$

With $T_{\text {cell, ref }}=25^{\circ} \mathrm{C}$ and $T_{\text {cell }}$ varies depending on the radiation and the ambient temperature $T_{a}$ according to the following linear relation:

$$
T_{\text {cell }}=T_{a}+\frac{(N O C T-20) G_{\beta}}{800}
$$

where NOCT is the Nominal Operating Cell Temperature.

For the reference temperature $T_{\text {cell, }}$ ref, the reference's reverse saturation current $I_{0}$, ref can be calculated from equation (23), where $I_{p v}=0$; corresponding to the open circuit case $V_{p v}=V_{o c \text {, ref. This current }}$ $I_{0, \text { ref }}$ is expressed by:

$$
I_{0, \text { ref }}=\frac{I_{s c, \text { ref }}}{\exp \left(\frac{q V_{o c, \text { ref }}}{n_{s} a K T_{c e l l, r e f}}\right)-1}
$$

The dependence of the reverse saturation current of the diode $I_{0}$, for any $T_{\text {cell }}$ temperature can be expressed by the following equation [23]: 


$$
I_{0}=I_{0, \text { ref }}\left(\frac{T_{\text {cell }, \text { ref }}}{T_{\text {cell }}}\right)^{\frac{3}{a}} \exp \left[\frac{q E_{g}}{a K}\left(\frac{1}{T_{\text {cell }, \text { ref }}}-\frac{1}{T_{\text {cell }}}\right)\right]
$$

Where $E_{g}$ is the Gap that means the energy of the band gap of the semiconductor, such as $E_{g}=1.2 \mathrm{eV}$ for poly-crystalline silicon at $25^{\circ} \mathrm{C}$.

\subsubsection{Rs model Parameter Extraction}

Figure 9 presents the simplified iterative algorithm of $R_{s}$ model.

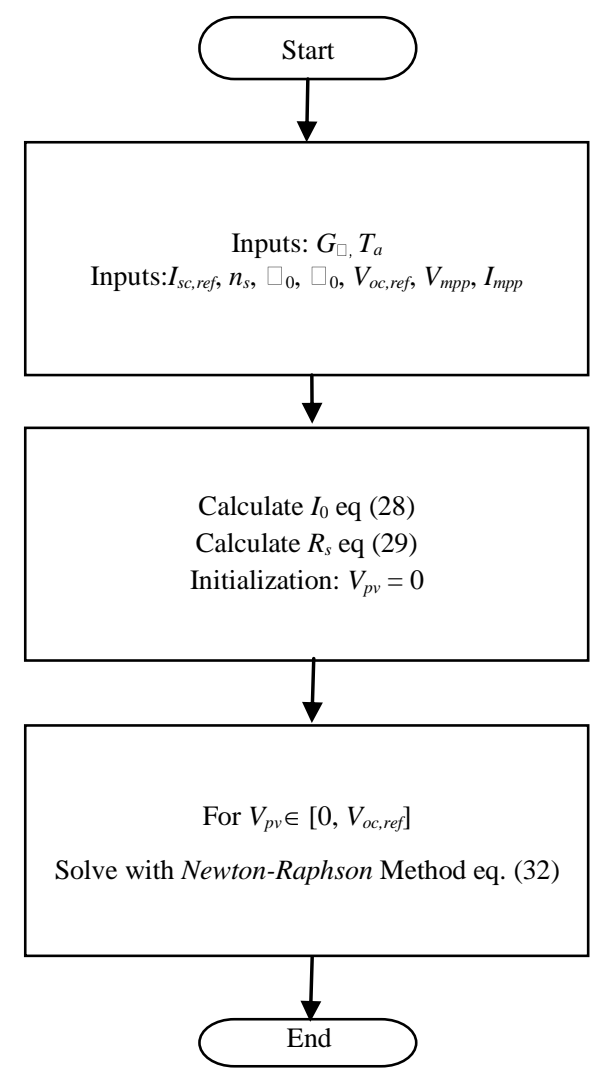

Figure 9. Algorithm Resolving the $R_{S}$ Model

By neglecting the term "-1"added to the exponential equation (23), the value of $R_{s}$ can be obtained by the following equation:

$$
R_{S}=-\left.\frac{d V_{p v}}{d I_{p v}}\right|_{V_{p v}=V_{o c}}-\frac{1}{X_{v}}
$$

with:

$$
X_{v}=q \frac{I_{s c}}{a K T_{\text {cell }}}
$$

The equation (29) term (-d $\left.V_{p v} / d I_{p v}\right)$ can be determined experimentally from the $I_{p v}-V_{p v}$ characteristic given by the manufacturer.

To solve the equation (23), it can be written in the following form: 


$$
I_{p v}-I_{p h}+I_{0}\left[\exp \left(\frac{q\left(V_{p v}+R_{s} I\right)}{n_{s} a K T_{\text {cell }}}\right)-1\right]=0
$$

So that we have:

$$
f(I)=I_{p v}-I_{p h}+I_{0}\left[\exp \left(\frac{q\left(V_{p v}+R_{s} I\right)}{n_{s} a K T_{\text {cell }}}\right)-1\right]=0
$$

The Newton-Raphson method is used for determining the solution of this equation (23), by applying the following iterative relation:

$$
I_{p v, k+1}=I_{p v}-\frac{f\left(I_{p v, k}\right)}{f^{\prime}\left(I_{p v, k}\right)}
$$

with:

$f\left(I_{p v}\right)$ : Function to solve and $f^{\prime}\left(I_{p v}\right)$ its derivative;

$I_{p v, k}: k^{\text {th }}$ iteration of the current;

$I_{p v, k+1}:(k+1)^{\text {th }}$ iteration of the current.

\subsection{Model with One Diode with $R s$ and $R p$}

\subsubsection{Presentation of the $R s-R p$ Model}

Some authors [24] have developed this model, shown in Figure 10. It's also based on the equivalent circuit with a diode in addition to the series resistor. This model takes account of the parallel resistor effect, called shunt resistor $\left(R_{p}\right)$. This model ensures that the maximum power of the model corresponds to the real maximum power of the PV module. In the case of this model, the current $I_{p v}$ is given by the equation below [25-26].

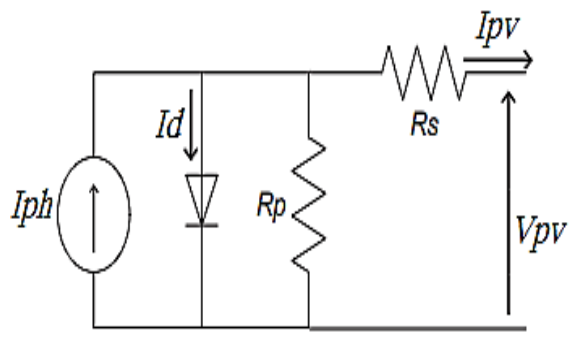

Figure 10. $R s-R p$ Model

$$
I_{p v}=I_{p h}-I_{d}-I_{s h}
$$

The photo-current is linearly dependent on solar radiation but also influenced by the temperature, according to the following relation:

$$
I_{p h}=\left(I_{p h, r e f}+\alpha_{0} \Delta T\right) \frac{G_{\beta}}{G_{\beta, r e f}}
$$

In the standard test conditions or nominal conditions $\left(G=1000 \mathrm{~W} / \mathrm{m}^{2}\right.$ and $\left.T=298 \mathrm{~K}\right)$, the expression of $I_{p h \text {,ref }}$ is given by :

$$
I_{p h, r e f}=\left(1+\frac{R_{s}}{R_{p}}\right) I_{s c, r e f}
$$


Therefore, the final expression of the photocurrent $I_{p h}$ is given by the following equation:

$$
I_{p h}=\left(\left(1+\frac{R_{s}}{R_{p}}\right) I_{s c, r e f}+\alpha_{0} \Delta T\right) \frac{G_{\beta}}{G_{\beta, r e f}}
$$

By application of the meshes law, the $I_{s h}$ current in the shunt resistor is expressed by [27]:

$$
I_{s h}=\frac{V_{p v}+R_{s} I_{p v}}{R_{p}}
$$

The diode current $I_{d}$ is given by:

$$
I_{d}=I_{0}\left[\exp \left(\frac{V_{p v}+R_{s} I_{p v}}{V_{t} a}\right)-1\right]
$$

with:

$$
V_{t}=\frac{n_{s} a K T_{\text {cell }}}{q}
$$

By replacing $T_{\text {cell }}$ in equation (40) by $T_{\text {cell, ref }}$, we obtain the thermal voltage $V_{t \text {,ref }}$ at the reference temperature $T_{\text {cell, ref, }}$ :

$$
V_{t, \text { ref }}=\frac{n_{s} a K T_{\text {cell, ref }}}{q}
$$

The reverse saturation current of diode $I_{0}$ given by (28) can be calculated by the following equation:

$$
I_{0}=\frac{I_{s c, r e f}+\alpha_{0} \Delta T}{\exp \left(\frac{V_{o c, r e f}+\beta_{0} \Delta T}{a V_{t}}\right)-1}
$$

Finally, the current $I_{p v}$ of the equation (34) becomes:

$$
I_{p v}=I_{p h}-I_{0}\left[\exp \left(\frac{V_{p v}+R_{s} I_{p v}}{V_{t} a}\right)-1\right]-\frac{V_{p v}+R_{s} I_{p v}}{R_{p}}
$$

\subsection{2. $R s-R p$ Model Parameter Extraction}

Some authors [24], suggest a method allowing the determination of the two $R_{s}$ and $R_{p}$ unknown parameters of the (43) equation. Their method is based on the fact that a unique pair $\left(R_{s}, R_{p}\right)$ exists that guaranties the equality between the maximum power $P_{\max , c}$ given the manufacturer and the maximum power $P_{\max , s}$ calculated using the model.

The relation between $R_{p}$ and $R_{s}$ can be determined by satisfying the condition of $P_{\max , c}=P_{\max , s}$ and solving the resulting equation as follows:

$$
\begin{aligned}
P_{\text {max }, s}=V_{m p p} & \left\{\begin{array}{l}
I_{p h}-I_{0}\left[\exp \left(\frac{q}{K T_{\text {cell }}} \frac{V_{m p p}+R_{s} I_{\text {mpp }}}{a n_{s}}\right)-1\right] \\
-\frac{V_{m p p}+R_{s} I_{\text {mpp }}}{R_{p}}
\end{array}\right\} \\
= & P_{\text {max }, c}
\end{aligned}
$$

From equation (44), the value of $R_{p}$ is determined, as indicated by the following equation: 


$$
R_{p}=\frac{V_{m p p}\left(V_{m p p}+I_{m p p} R_{s}\right)}{\left\{V_{m p p} I_{p h}-V_{m p p} I_{0} \exp \left[\frac{\left(V_{m p p}+I_{m p p} R_{s}\right)}{n_{s} a} \frac{q}{K T}\right]+V_{m p p} I_{0}-P_{\text {max }, c}\right\}}
$$

This latter equation shows that for each value of $R_{s}$ corresponds a value of $R_{p}$ such that the characteristic $I_{p v}-V_{p v}$ passes by the point $\left(V_{m p p}, I_{m p p}\right)$. In order that the iterative process starts, the initial estimation of $R_{s}$ and $R_{p}$ is necessarily. The $R_{p}$ initial value $R_{p, \min }$ can be calculated by the use of the equation:

$$
R_{p, \text { min }}=\frac{V_{m p}}{I_{s c, r e f}-I_{m p}}-\frac{V_{o c, r e f}-V_{m p}}{I_{m p}}
$$

Simplified iterative algorithm of $R_{s}-R_{p}$ model is presented in Figure 11, with $\mathrm{x}_{1}, \mathrm{x}_{2}, \mathrm{x}_{3}, \mathrm{x}_{4}$ and $\mathrm{x}_{5}$ are respectively the equations $42,46,37,45$ and 35 .

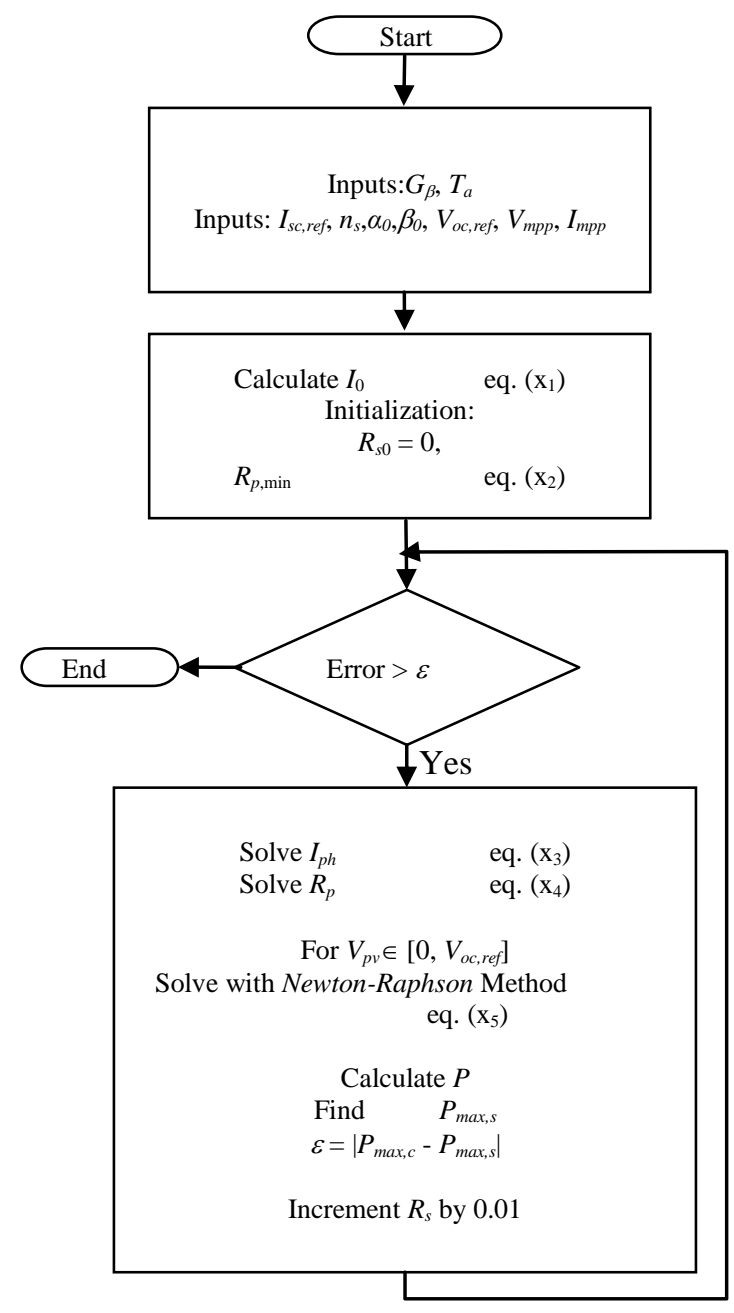

Figure 11. Algorithm Resolving the $R s-R p$ Model

\subsection{Model Two Diode}

\subsubsection{Presentation of Model Two Diode}

Other authors [28] presented this model. It's a model that was simplified and uses only four parameters comparatively to six or more in other models of two diodes. It's founded on the equivalent circuit 
given by the Figure 12. We realize this circuit by connecting in parallel two diodes. The saturation current of the two diodes are $I_{01}$ and $I_{02}$ and the ideality factors are $a_{1}$ and $a_{2}$.

The following equation describes the output current of the PV generator:

$$
I_{p v}=I_{p h}-I_{d 1}-I_{d 2}-\left(\frac{V_{p v}+R_{s} I_{p v}}{R_{p}}\right)
$$

with $I_{d 1}$ and $I_{d 2}$ the respective currents of the diodes 1 and 2.They are expressed by the equations (48) and (49):

$$
\begin{aligned}
& I_{d 1}=I_{01}\left[\exp \left(\frac{V_{p v}+R_{s} I_{p v}}{a_{1} V_{T 1}}\right)-1\right] \\
& I_{d 2}=I_{02}\left[\exp \left(\frac{V_{p v}+R_{s} I_{p v}}{a_{2} V_{T 2}}\right)-1\right]
\end{aligned}
$$
(equation 50):

Authors who developed this model [28], assumes that the saturation currents $I_{01}$ and $I_{02}$ are equal

$$
I_{0}=I_{01}=I_{02}=\frac{\left(I_{s c, r e f}+\alpha_{0} \Delta T\right)}{\exp \left[\frac{\left(V_{o c, r e f}+\beta_{0} \Delta T\right)}{\left(\left(a_{1}+a_{2}\right) / p\right) V_{t}}\right]-1}
$$

According to the Shockley diffusion theory, $a_{1}$ must be equal to 1 [28-29]. A value of $a_{2}$ greater than or equal to 1.2 gives a better match between the proposed model and practice characteristics $I_{p v}-V_{p v}$.

The value of the variable $p$ can be chosen greater of equal to 2.2 since $a_{1}=1$ and $\left(a_{1}+a_{2}\right) / p=1$ [28].

The photo-current $I_{p h}$ can be calculated, as a function of the temperature of the cells $T_{\text {cell }}$ and the radiation $G_{\beta}$, as previously for the case of model $R_{s}-R_{p}$.

$$
I_{p h}=\left(I_{p h, r e f}+\alpha_{0} \Delta T\right) \frac{G_{\beta}}{G_{\beta, r e f}}
$$

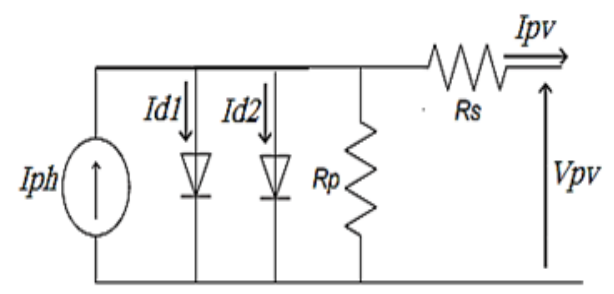

Figure 12. Two Diodes Model

\subsubsection{Parameter Extraction of Model Two Diode}

The value of the resistor $R_{p}$ is determined, as in the case of the model $R_{p}-R_{s}$, satisfying the condition of equality between the power given by the manufacturer $P_{\max , c}$, and the maximum power $P_{\max , s}$ calculated by the model.

$$
R_{p}=\frac{V_{m p p}\left(V_{m p p}+R_{s} I_{m p p}\right)}{\left[V_{m p p}\left(I_{p h}-I_{d 1}-I_{d 2}\right)-P_{\max , c}\right]}
$$


The initial value for the resistor $R_{s}$ is $R_{s 0}=0$ howeverthe initial value of the resistor $R_{p 0}$ is estimated by:

$$
R_{p}=\frac{V_{m p p}\left(V_{m p p}+R_{s} I_{m p p}\right)}{\left[V_{m p p}\left(I_{p h}-I_{d 1}-I_{d 2}\right)-P_{\max , c}\right]}
$$

The simplified iterative algorithm of the two diodes model is shown in Figure11, with $\mathrm{x}_{1}, \mathrm{x}_{2}, \mathrm{x}_{3}, \mathrm{x}_{4}$ and $\mathrm{x}_{5}$ are respectively the equations $50,53,51,52$ and 47 .

\section{RESULTS AND DISCUSSION}

\subsection{Estimation of the Incident Solar Radiation}

In order to validate the used model to predict the real global solar radiation received by horizontal surface, we conducted the measurements on a sample recorded by the weather station installed in the site under study. Those measurements cover a long period stretching from 2009 to 2013. The Figures 13 to 16 compare the solar radiation given by the station with the one delivered by our model developed under Matlab for 4 days: November $15^{\text {th }}, 2013$, March $12^{\text {th }}, 2012$, July 01 ${ }^{\text {st }}, 2011$ and September $11^{\text {th }}, 2009$.

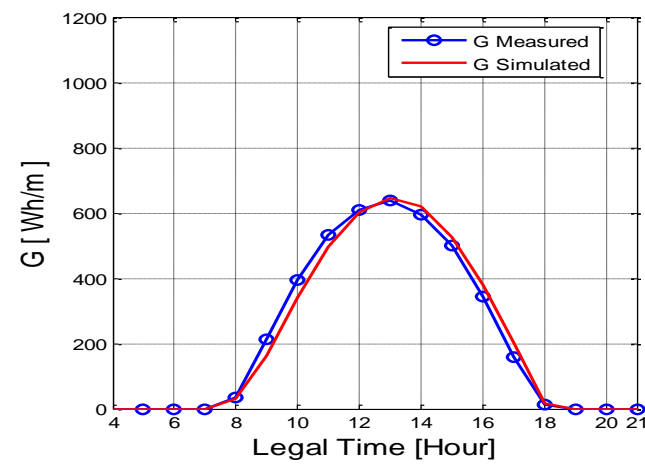

Figure 13. Global Solar Radiation Received on a Horizontal Surface on November $15^{\text {th }}, 2013$.

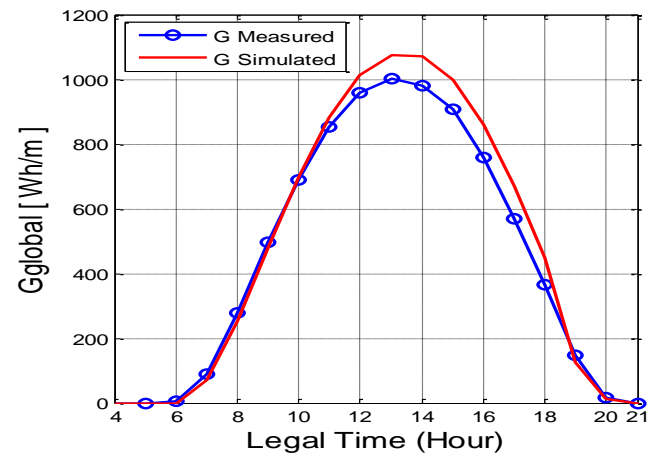

Figure 15. Global Solar Radiation Received on a Horizontal Surface on July 01st 2011

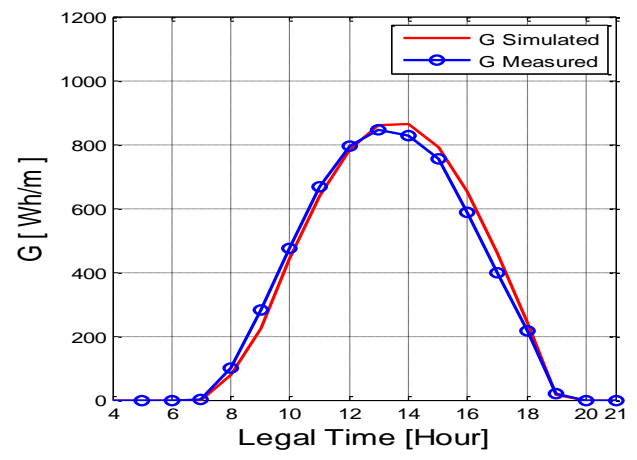

Figure 14. Global Solar Radiation Received on a Horizontal Surface on March 12th, 2012

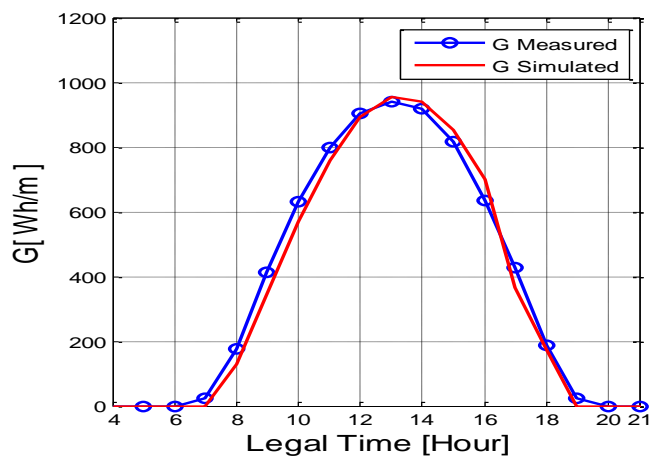

Figure 16. Global Solar Radiation Received on a Horizontal Surface on September 11 ${ }^{\text {th }}, 2009$

In order to judge the reliability of the proposed model at our site and in order to determine the error of the incident radiation, we calculate the instantaneous relative error by the following equation: 


$$
E r r=\frac{G_{\text {measured }}-G_{\text {calculated }}}{G_{\text {measured }}}
$$

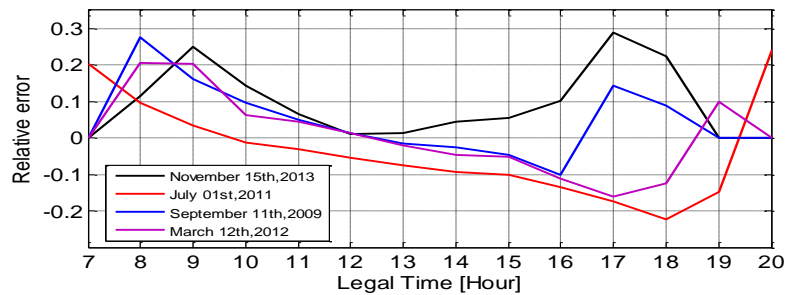

Figure 17. Relative Error of the Global Solar Radiation Received on a Horizontal Surface for the Selected Four Days

The error's values for the four days of the selected sample are showing in Figure 17. These values show that the instantaneous relative error does not exceed 10\% from 10:00 AM to 4:00 PM, and the maximum of this error is $27 \%$ for November $15^{\text {th }} 2013,06: 00$ PM. This confirms the validity of our model.

For inclined surfaces of angles $\beta=15^{\circ}, 30^{\circ}, 45^{\circ}$ and $60^{\circ}$, we have represented in figure 18 the global solar radiation $G_{\beta}$ received on these surfaces. We observe an increase of solar radiation received by the inclined surfaces compared to the horizontal ones, which leads to the increasing of the power produced by the PVG.

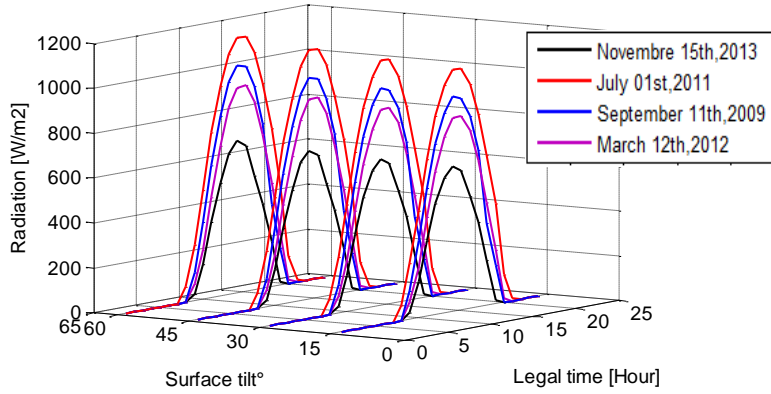

Figure 18. Global Solar Radiation for Different Inclinations at the 4 Selected Days

\subsection{Extracting the Electrical Parameters of the PVG}

The PVG, which is the object of our characterization, is of type BP Solar MSX-64. Its electrical characteristics are provided in Table 2 [30].

Table 2. Electrical Characteristics of the PV Panel MSX-64

\begin{tabular}{lc}
\hline \multicolumn{1}{c}{ Maximum power Pmax, $c$} & $64 \mathrm{~W}$ \\
\hline Voltage at maximum power Vmpp & $17.5 \mathrm{~V}$ \\
Current at maximum power Impp & $3.66 \mathrm{~A}$ \\
Short-circuit current $I s c$, $r e f$ & $4 \mathrm{~A}$ \\
Open-circuit voltage $V o c, r e f$ & $21.3 \mathrm{~V}$ \\
Temperature coefficient $\beta_{0}$ of $V_{o c}$ & $-(80 \pm 10) \mathrm{mV} /{ }^{\circ} \mathrm{C}$ \\
Temperature coefficient $\alpha_{0}$ of $I_{s c}$ & $(0.065 \pm 0.015) \% /{ }^{\circ} \mathrm{C}$ \\
Temperature coefficient $\gamma_{0}$ of power & $-(0.5 \pm 0.05) \% /{ }^{\circ} \mathrm{C}$ \\
NOCT & $47 \pm 2{ }^{\circ} \mathrm{C}$ \\
\hline
\end{tabular}

For the three models used to model and characterize our PVG, we have represented in the same Figures 19 to 21, the output characteristics $I_{p v}-V_{p v}$ and simulated power $P_{p v}-V_{p v}$ as well as those given by the

Modelling and Predicting of the Characteristics of a Photovoltaic Generator on ... (Mustapha Elyaqouti) 
manufacturer, under radiation $G_{\beta}=1000 \mathrm{~W} / \mathrm{m}^{2}$ and temperatures of $25{ }^{\circ} \mathrm{C}, 50{ }^{\circ} \mathrm{C}$ and $75^{\circ} \mathrm{C}$.
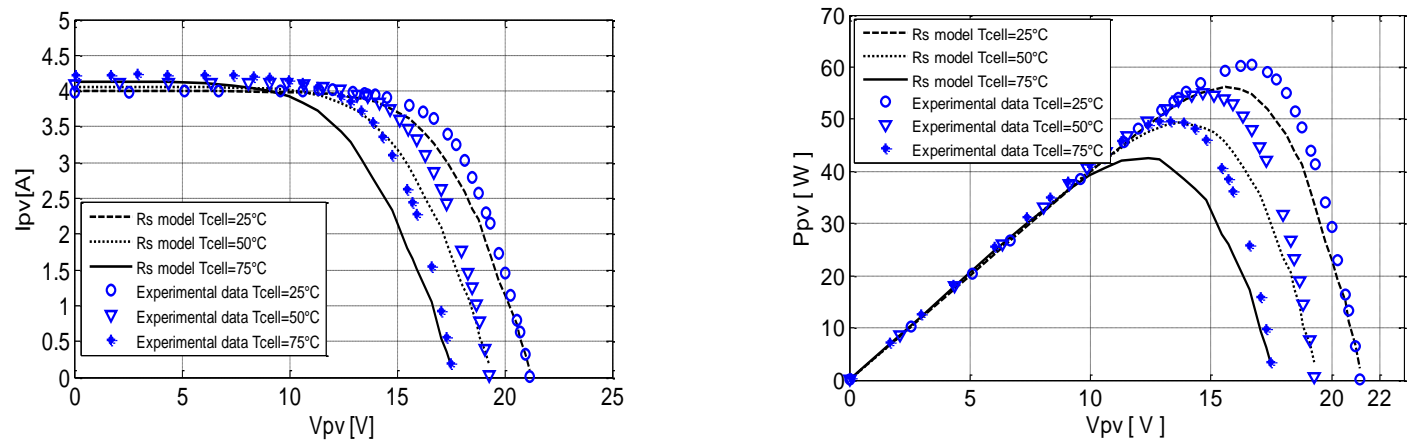

Figure 19. Extracted Characteristics $I_{p v}-V_{p v}$ and $P_{p v}-V_{p v}$ from $R_{s} \operatorname{Model}\left(\right.$ for $G_{\beta}=1000 \mathrm{~W} / \mathrm{m}^{2}$ and $T_{c e l l}=25^{\circ} \mathrm{C}$, $50^{\circ} \mathrm{C}$ and $75^{\circ} \mathrm{C}$ )
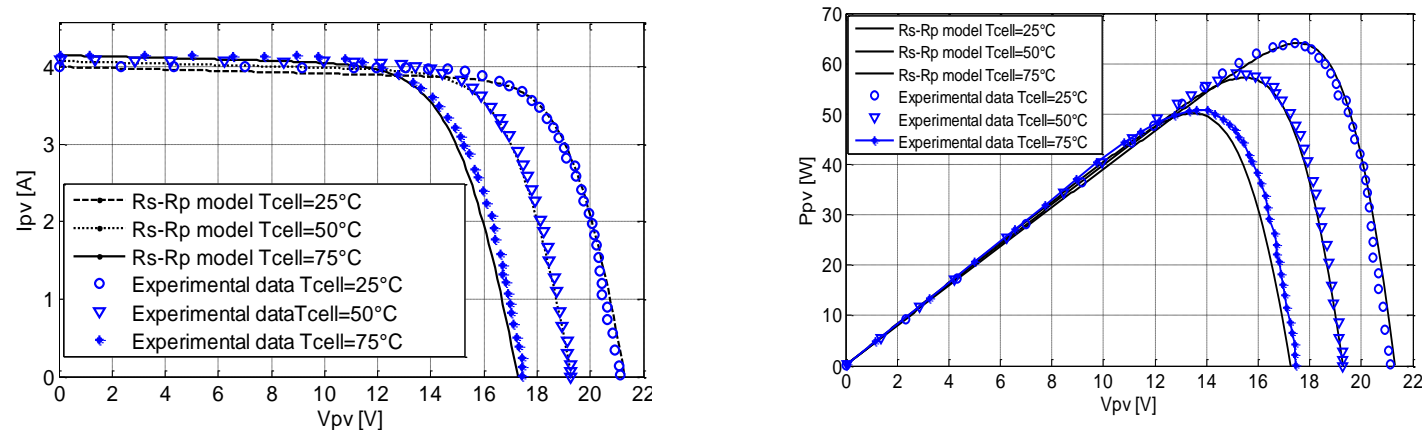

Figure 20. Extracted characteristics $I_{p v^{-}} V_{p v}$ and $P_{p v^{-}} V_{p v}$ from $R s-R p$ model (for $G_{\beta}=1000 \mathrm{~W} / \mathrm{m}^{2}$ and $T_{\text {cell }}=25,50$ and $75^{\circ} \mathrm{C}$ )
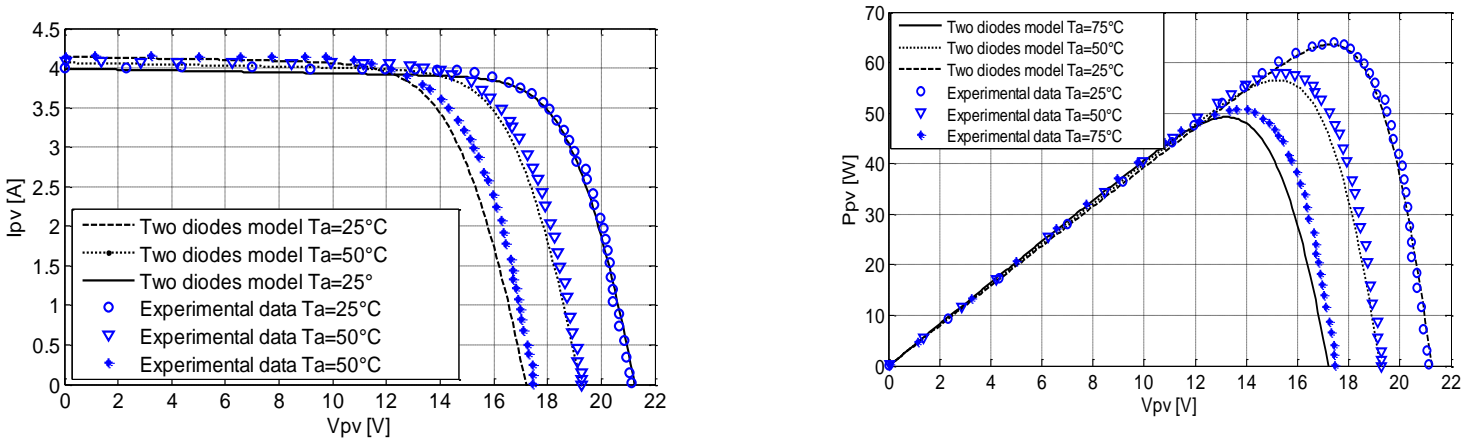

Figure 21. Extracted characteristics $I_{p v}-V_{p v}$ and $P_{p v}-V_{p v}$ from two diodes model (for $G_{\beta}=1000 \mathrm{~W} / \mathrm{m}^{2}$ and $T_{\text {cell }}=25,50$ and $75^{\circ} \mathrm{C}$ )

Table 3. Extracted Parameters for the three models

\begin{tabular}{lccc}
\hline Parameters & $R s$ Model & $R s-R p$ Model & Model 2 diodes \\
\hline$R s(\Omega)$ & 0.32 & 0.28 & 0.26 \\
$R p(\Omega)$ & - & 115.70 & 123.45 \\
$P \operatorname{Pmax}, s(\mathrm{~W})$ & 56.26 & 64.05 & 64.05 \\
Pmax,$c(\mathrm{~W})$ & 64.05 & 64.05 & 64.05 \\
Erreur $(\mathrm{W})$ & 7.79 & 0.0001 & 0 \\
$I_{0}(\mathrm{~A})$ & $7.51 .10^{-7}$ & $3.813810 .10^{-10}$ & $3.988721 .10^{-10}$ \\
\hline
\end{tabular}


As a result of the comparison of the various figures 19 to 21 , we observe that, for both models, $R_{s}-R_{p}$ and two diodes, the simulated output characteristics reproduce quite faithfully the experimental data of the manufacturer contrarily to $R_{s}$ model.

After treatment of the three proposed models, we summarize in Table 3, the results for the electrical parameters extracted from the modeled PVG.

In order to confirm the previous observations and to estimate the precision of the extracted parameters from the suggested models that represented the $I_{p v}-V_{p v}$ characteristics, we calculated the absolute error Era that represents the difference between the $I_{p v}$ measured currents by the manufacturer and those calculated by modeling and simulated. The following relation expresses the absolute difference Era:

$$
\text { Era }=\left|I p v_{\text {measured }}-I p v_{\text {calculated }}\right|
$$

Thus, the evaluated errors are shown in Figure 22 in the case of $I_{p v}-V_{p v}$ characteristics in the weather conditions $G_{\beta}=1000 \mathrm{~W} / \mathrm{m}^{2}$ and $T_{\text {cell }}=25{ }^{\circ} \mathrm{C}, 50{ }^{\circ} \mathrm{C}$ and $75^{\circ} \mathrm{C}$.

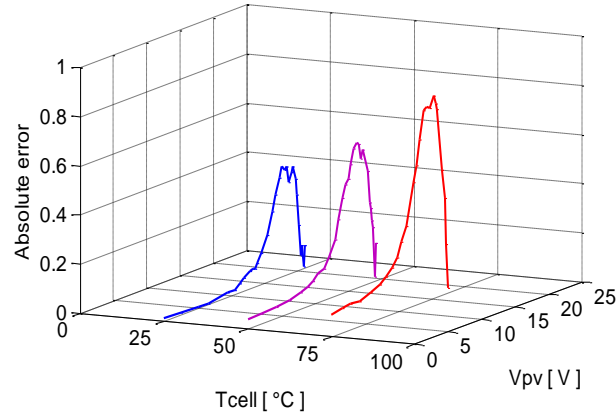

(a)

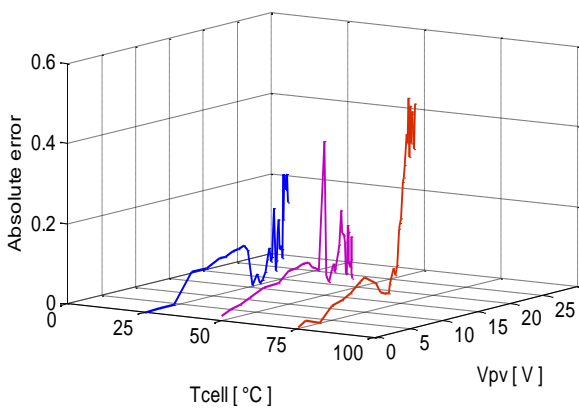

(b)

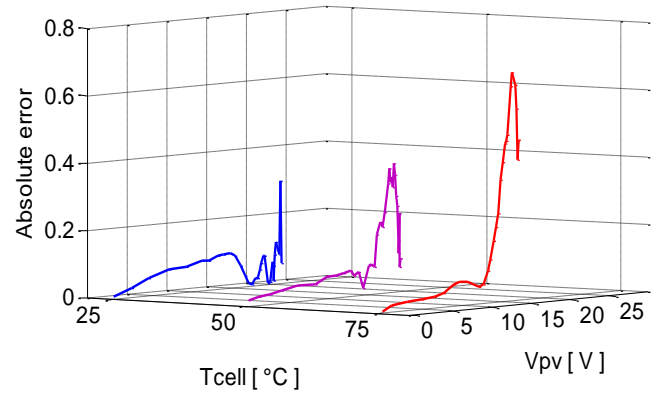

(c)

Figure 22. Absolute Errors Evaluating the three models: Rs (a), Rs-Rp (b) and the 2diodes (c)

Basing on the Figure 22, we can notice that for both models $R_{s}-R_{p}$ and a two diode model, the absolute deviations Era are quite low. This is in agreement with the results that Villalva and al found in [24] during the modelling and the simulation of two modules PV (KC200GT and MSX60) by the application of the $R_{s}-R_{p}$ model and with the results that Khassif and al found in [28] to model and simulate the electric behavior of six PV modules (MSX-60, KG200GT, S36, SG150-PC, SP 70 and ST40). For that reason, those the two models will be selected to describe the output characteristic of the PV module under test; BP Solar MSX-64.

\subsection{Prediction of the Power Produced by PVG}

The figure 23 shows the output characteristic as well as the estimated electrical power produced by the BP Solar MSX-64, for different inclinations, November 15th 2013 at 2:00 PM.

Finally, the adopted appraoch allows us to predict $I_{p v}-V_{p v}$ and $P_{p v}-V_{p v}$ characteristics of a PV module for any orientation and any location.

Modelling and Predicting of the Characteristics of a Photovoltaic Generator on ... (Mustapha Elyaqouti) 

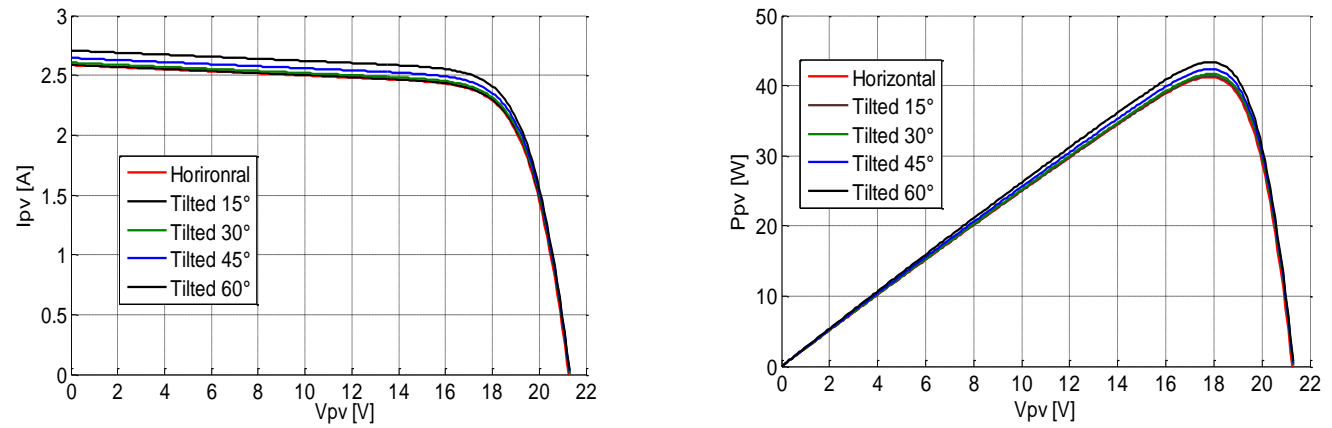

Figure 23. Estimated characteristics $V_{p v}-I_{p v}$ and $P_{p v}-V_{p v}$ at November $15^{\text {th }} 2013$ at02:00 PM

\section{CONCLUSION AND PERSPECTIVES}

The work presented in this paper allowed us to predict the output current-voltage and the powervoltage characteristics of a photovoltaic generator installed in a selected location, and consequently estimating the daily, monthly and yearly production of electricity, in other words, the determination of the photovoltaic system performance.

The measurements collected by the weather station installed in our laboratory, has allowed us to validate the selected model for the prediction and estimation of the incident solar radiation on the horizontal surfaces.

Modeling and characterization the photovoltaic generator allowed us to confirm that the $R_{s}-R_{p}$ model and the model with two diodes provide a good agreement between the manufacturer experimental data and the simulated data.

The prospects of our work are, firstly to connect the modeled PVG to a storage element through an adaptation floor provided with a search function of a maximum power point tracking (MPPT) to extract the maximum of power. Secondly, we aim the insertion of this PV conversion chain in a hybrid system of renewable energy.

\section{REFERENCES}

[1] A. Orioli, A. Di Gangi. A procedure to calculate the five-parameter model of crystalline silicon photovoltaic modules on the basis of the tabular performance data. Applied Energy. 2013; 102: 1160-1177.

[2] L. Stoyanov. Etude de différentes structures de systèmes hybrides à sources d'énergie renouvelables. Thèse de doctorat. Université de Corse Pasquale Paoli. 2011.

[3] A.D. Jones and C.P. Underwood. A Modeling Method for Building-integrated Photovoltaic Power Supply. Building Services Engineering Research and Technology. 2002; 23(3): 167-177.

[4] S. Farhat, R.Alaoui, A. Kahaji, L. Bouhouch. MPPT Efficiency test by neural netwoks and P\&O algorithm, International Review of Electrical Engineering (IREE). 2013; 8(5): 1548-1555.

[5] S. Farhat, R. Alaoui, A. Kahaji, L. Bouhouch. P\&O and Incremental Conductance MPPT Implementation. International Reviewof Electrical Engineering (IREE). 2015; 10(1): 116-122.

[6] R. Chenni, E. Matagne, M. Khennane. Study of solar radiation in view of photovoltaic systems optimization. Smart Grid and Renewable Energy. 2011; 2: 367-374.

[7] T. Maatallah, S. El Alimi, S. Ben Nassrallah. Performance modeling and investigation of fixed, single and dual-axis tracking photovoltaic panel in Monastir city, Tunisia. Renewable and Sustainable Energy Reviews. 2011; 15(8): 4053-4066.

[8] http://fr.vikidia.org/wiki/Mouvement_apparent_du_Soleil

[9] M.A. Camara, Modélisation du stockage de l'énergie photovoltaïque par super-condensateurs, Thèse de doctorat, Université Paris-Est Creteil. 2011.

[10] G. Notton, C. Poli, S. Vasileva, M.L. Nivet, J.L Canaletti, C. Cristofari. Estimation of hourly global solar irradiation on tilted planes from horizontal one using artificial neural networks. Energy. 2012; 39: 166-179.

[11] R. PonVengatesh, S. Edward Rajan. Investigation of cloudless radiation with PV module employing MatlabSimulink. Solar Energy. 2011; 85: 1727-1734.

[12] Sidi Mohammed Elamin Bekkouche. Modélisation thermique de quelques dispositifs solaire. Thèse de doctorat, Université Abou-Bakr Belkaid Tlemcen. 2009.

[13] A. M'Raoui, S. Mouhous, A. Malek, B. Benyoucef. Etude statistique du rayonnement solaire à Alger. Revue des Energies Renouvelables. 2011; 14(4): 637-648. 
[14] B. Ould Bilal, V. Sambou, C.M.F. Kebe, M. Ndongo, P.A Ndiaye. Etude et modélisation du potentiel du site de Nouakchott et de Dakar. Journal des Sciences. 2007; 7(4): 57-66.

[15] E.D. Mehleri, P.L. Zervas, H. Sarimveis, J.A. Palyvos, N.C. Markotos. Determination of the optimal tilt angle and orientation for solar photovoltaic arrays. Renewable Energy. 2010; 35: 2468-2475.

[16] Andrea Padovan, Davide Del Col. Measurment and modeling of solar irradiance components on horizontal and tilted planes. Solar Energy. 2010; 84: 2068-2084.

[17] P. Henri Communay. Héliothermique: le gisement solaire méthodes et calculs. Groupe de recherche et d'édition. 2002.

[18] M. Iqbal, An introduction to solar radiation, Academic de press, Canada, 1983, ISBN: 0-12-373752-4, 1983.

[19] T.M. Klucher. Evaluation of models to predict insolation on tilted surfaces, Solar Energy. 1979; 23(2): 111-114.

[20] Djamila Rekioua, Ernest Matagne. Optimization of PhotovoltaicPower Systems, Book, Springer, ISBN 978-14471-2348-4. 2012.

[21] Fu Qiang, Tong Nan. A strategy research on MPPT technique in photovoltaic power generation system. TELEKOMINIKA. 11(12): 7627-7633.

[22] Mohamed Louzazni, EL Hassan Aroudan, Hanane Yatimi. Modeling and simulation of solar power source for a clean energy without pollution. International Journal of Electrical and Computer Engineering (IJECE). 2013; 3(4): 568-576.

[23] Francisco M. Gonzalez-Longatt. Model of photovoltaic Module in Matlab, 2DoCongresolbero Americano de Estudiantes de Ingenieria Electrica, Electronicay Computacion. CIBELEC. 2005.

[24] M. Gradella Villalva, J. Rafael Gazoli and E. Ruppert Filho. Comprehensive Approach to Modelling and Simulation of Photovoltaic Arrays. IEEE Transactions on Power Electronics. 2009; 24(5): 1198-1208.

[25] Mohammed Yaichi, Mohammed Karim Fellah, Abdelkrim Mammeri. A Neural Network Based MPPT Technique controller for pumping system. International Journal of Power Electronics and Drive System (IJPEDS). 2014; 4(2): 241-255.

[26] Sangita R. Nandurkar, Mini Rajeev. Design of photovoltaic array with MPPT control techniques. International Journal of Applied Power Engineering (IJAPE). 2014; 3(1): 41-50.

[27] Sobhan Dorahaki. A survey on maximum power point tracking methods in photovoltaic power systems. Bulletin of Electrical Engineering and Informatics. 2015; 4(3):169-175.

[28] K.Ishaque, Zainal Salam, Hamed Taheri. Simple fast and accurate two-diode model for photovoltaic modules. Solar Energy Materials \& Solar cells. 2011; 95: 586-594.

[29] C. Sah, Fundamentals of solid-state electronics, World Scientific publishing Co. Pte, Library of Congress Cataloging-in-Publication Data, ISBN 9810206372, 1991.

[30] https://www.smud.org/en/about-smud/environment/renewable-energy/documents/solar-regatta-photovoltaicspecs.pdf

\title{
BIOGRAPHIES OF AUTHORS
}
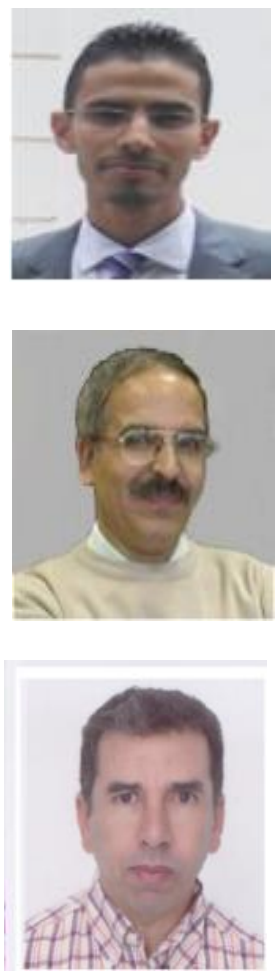

Mustapha Elyaqouti was born in Agadir, Morocco, in 1984. He received the technical University degree (DUT) in Electrical Engineering from the High School of Technologies of Agadir (EST Agadir), in 2006. He received his BSc degree in physics and a post graduate degree in Materials Engineering and energetic environment from Ibn Zohr University, in 2010 and 2012. His research, in the context of national doctoral thesis, focuses on the thematic of Renewable Energies. The doctoral investigation took place in the Research Team in advanced Technologies and Engineering of Renewable Energies (ERTAIER) Agadir Morocco

Lahoussine Bouhouch Professor of higher education at the ESTA (High School of Technologies of Agadir), IbnZohr University, Agadir, Morocco. PhD Electrical Engineering at the Nancy I University, France in 1988 and state doctorate in Electrical in 2007. Responsible of the research team ERTAIR (Research Team in Advanced Technologies and Engineering of Renewable Energies). His research focuses on topics related to renewable energy, instrumentation and electromagnetic compatibility (EMC)

\begin{abstract}
Ahmed Ihlal, was born and brought up in Morocco. He studied Physics and Chemistry and holds, in 1984, his BSc degree (LicenceEs-Sciences Physique) in Solid State Physics from the University Mohamed V, Rabat - Morocco. He then joined Paris VII University - France, where he got, in 1985, a MSc. degree (DEA: Diplome des Etudes Approfondies) in Solar Energy. He pursued his research on the studies and got, in 1988, a $\mathrm{PhD}$ degree from the University of Caen BasseNormandie - France. Dr. A. Ihlal started his teaching career on I988 as Assistant Professor in the faculty of Science at University Ibn Zohr. Then he holds a "Doctorat d'Etat" thesis in 1995. He is currently Full Professor in Faculty of Sciences, University Ibn Zohr, Agadir Morocco. He is head of the group working on developing cost effective processes for the
\end{abstract}

Modelling and Predicting of the Characteristics of a Photovoltaic Generator on ... (Mustapha Elyaqouti) 
fabrication of CIGS and CZTS absorber layers, buffer layers and TCOs. He is working on PV and CSP systems as well. He has published 60 scientific papers, and acted as a referee for numerous international journals. He has contributed to the organization of numerous national and international conferences and was a member of scientific committees for several international conferences. He is supervising $\mathrm{PhD}, \mathrm{MSc}$ as well as BSc students in the field of PV and CSP. He is an expert of the CNRST in the field of renewable energies. 